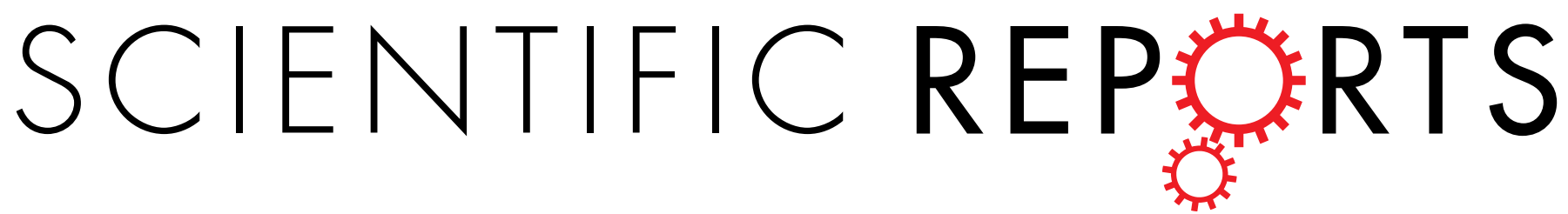

\title{
Corrigendum: Label-Free Characterization of Emerging Human Neuronal Networks
}

Mustafa Mir, Taewoo Kim, Anirban Majumder, Mike Xiang, Ru Wang, S. Chris Liu, Martha U. Gillette, Steven Stice \& Gabriel Popescu

Scientific Reports 4:4434; doi: 10.1038/srep04434; published online 24 March 2014; updated 30 June 2015

The Supplementary Information that accompanies this study was omitted from the original version of this Article. 